\title{
Evaluation of the Load Carrying Capacity of Short RC Columns Strengthened with a Novel Cementitious Material by Using FEA
}

\author{
Ionut Ovidiu TOMA ${ }^{1, a}$, Daniel COVATARIU ${ }^{1, b}$, Irina LUNGU ${ }^{2, c}$ \\ and Mihai BUDESCU ${ }^{1, d}$
}

${ }^{1}$ Technical University "Gheorghe Asachi of lasi", Faculty of Civil Engineering and Building Services, Department of Structural Mechanics, no. 43 ${ }^{\text {rd }}$, Prof.dr.doc. D. Mangeron Blvd., 700050, lasi,

Romania

${ }^{2}$ Technical University "Gheorghe Asachi of lasi", Faculty of Civil Engineering and Building Services, Department of Transportation Infrastructure and Foundations, no. 43 ${ }^{\text {rd }}$, Prof.dr.doc. D. Mangeron Blvd., 700050, lasi, Romania

a iotoma@ce.tuiasi.ro (corresponding author), ${ }^{b}$ covadan@ce.tuiasi.ro, cilungu@tuiasi.ro, dmbudescu@tuiasi.ro

Keywords: constitutive law, finite element analysis (FEA), jacketing, load carrying capacity.

\begin{abstract}
Numerical simulations based on the Finite Element Method (FEM) have become an important tool in studying various phenomena of interest to both researchers and practitioners alike. The recent advances in computational power coupled with accurate mathematical models have made FEM an indispensable tool for investigating complex loading states and material behavior that are frequently met in civil engineering. Strengthening of existing $\mathrm{RC}$ columns is becoming a pressing issue in the field of civil engineering due to the necessity of meeting new safety requirements for the buildings located in active seismic areas. Jacketing is a widely used method for strengthening of reinforced concrete columns showing good results in terms of increased strength and stiffness but with the addition of some unwanted effects amongst which the added dead weight is of primary importance in case of an earthquake. The paper presents the results obtained by means of Finite Element Analysis (FEA) on the load carrying capacity of short RC columns strengthened with a novel Cementitious material that may be the solution to lighter structures and lower added costs compared to other existing methods.
\end{abstract}

\section{Introduction}

During the recent seismic events it was observed that the partial or total collapse of reinforced concrete frame structures could be tied to the shear failure of columns. The shear failure of reinforced concrete (RC) columns rather than bending under lateral deformations is the key characteristic of short columns. Because of this, as a general rule, the short columns should be avoided in structures located in active seismic areas due to weak load-deformation behavior exhibited during an earthquake. Short columns are generally considered to have shear span to depth ratio of less than $2.5[1,2]$. Such elements are incorporated into structures either as part of the original design or as a result of the changes that took place during the life time of a building. Members that were originally conceived as short columns may not pose significant problems when subjected to seismic loads since every precaution has been taken during the design stage. Still, due to their significantly higher stiffness compared to slender columns, there are cases when the brittle failure of such members may render a structure unusable, as shown in Fig. 1 [3], or may even trigger the collapse.

However, there are cases when, due to later changes in the layout of the structure, the original slender columns become short. This may be the case of non-structural enclosure walls that shorten the effective length of the column leading to important changes in its behavior during a seismic event, Fig. 2 [4]. According to the Global Earthquake Model (GEM) Building Taxonomy [4], such members are called captive columns. Since understanding the behavior of such structural members is of paramount importance, especially for buildings located in active seismic areas, the issue has caught the attention of many researchers and practitioners alike [5-7]. 
The ageing of the RC built infrastructure coupled with ever increasing performance requirements in modern design codes has led to a demand in maintenance, repair and strengthening measures. An effective strengthening technique is the confinement of concrete by using external FRP jackets [8, 9]. Although FRP jackets are easy to apply and do not change the appearance of the structure, there are no usable practical guidelines developed by code committees.

Cementitious materials, on the other hand, are widely used in the strengthening and rehabilitation of buildings due to low manufacturing costs and the existence of code provisions. However, the downsides are related to the long duration of the rehabilitation process and the added self weight to the structure [10]. Moreover, the bond between the new and the existing, old, concrete is usually considered to be the weak link in the repaired structure [11]. There two frequently used methods of strengthening concrete structures either by using hardened concrete elements, Fig. 3, or by using fresh concrete with or without additional reinforcement. The former method is more common in precast / prestressed structures such as viaducts and bridge decks, whereas the latter is mainly used in other types of buildings. There are cases when a minimum downtime for repairing is required. Consequently, this results in the use of mineral binders with fast setting time and high early strength [12-14].
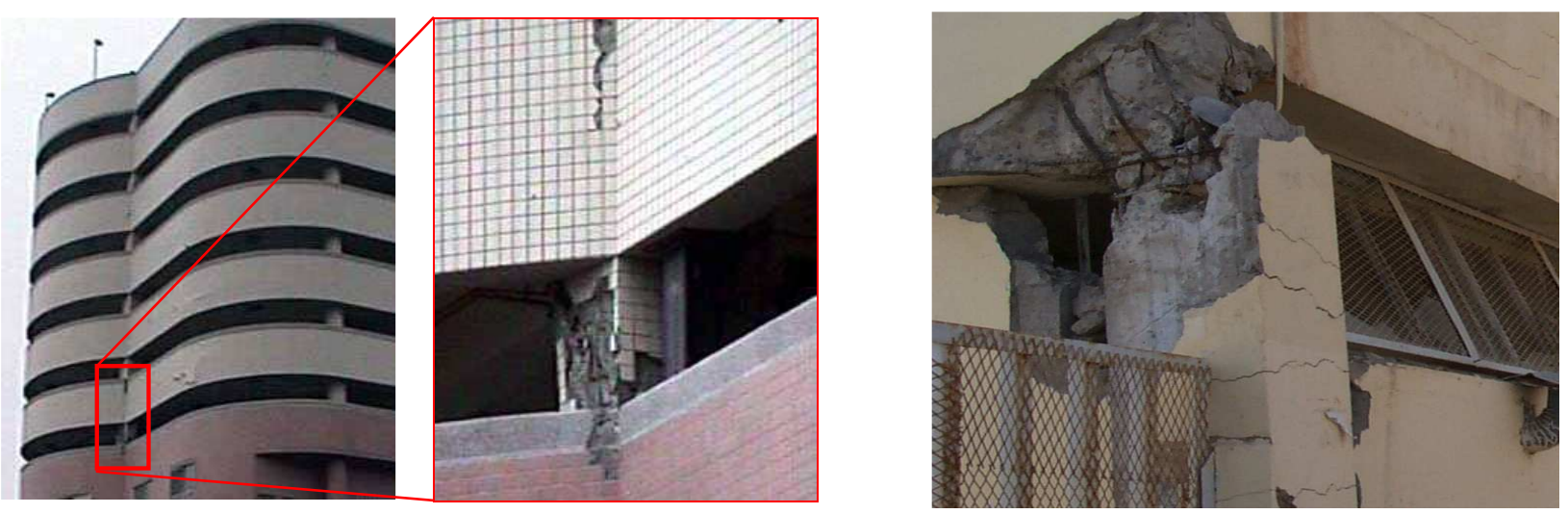

Fig. 1 Collapsed short column in a parking place during the 1999 Chi-Chi earthquake in Taiwan [3]
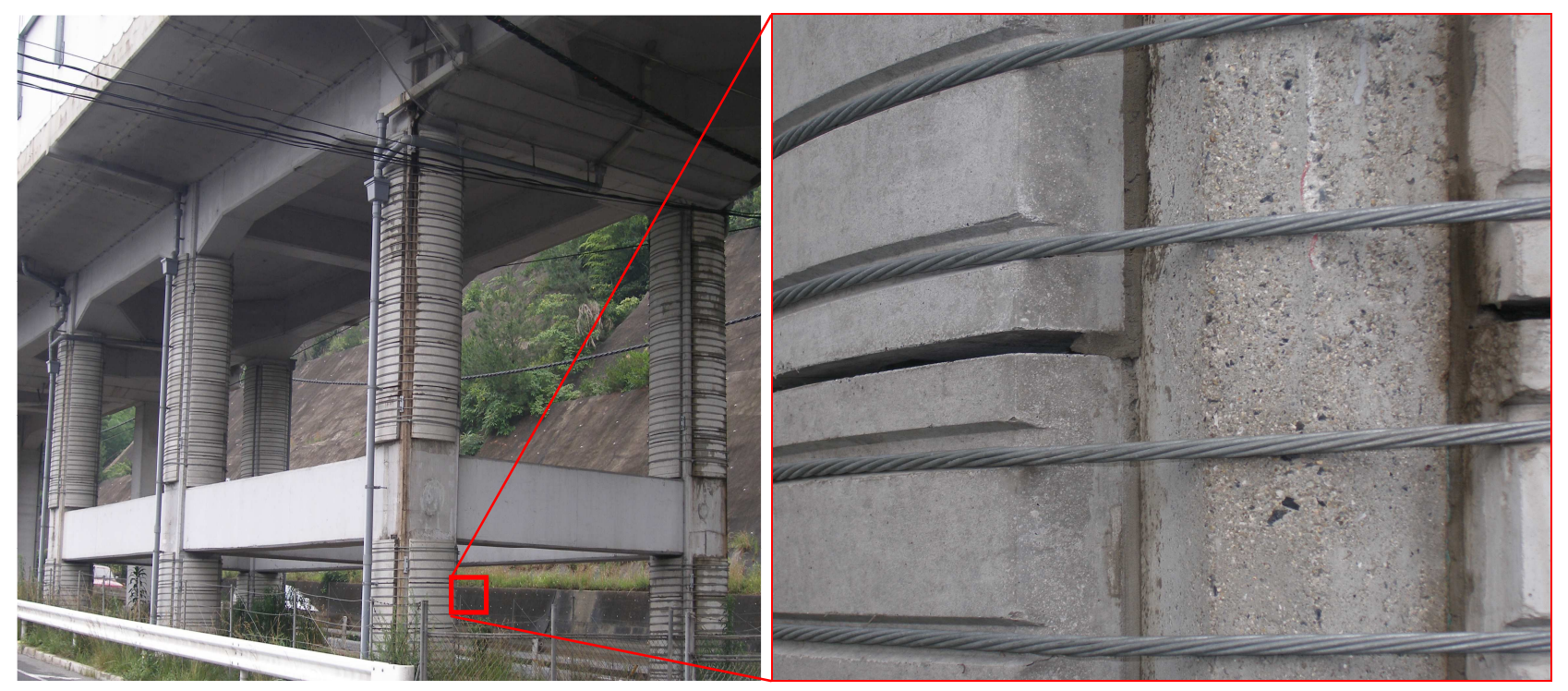

Fig. 3 Strengthened bridge pier for the shinkansen tracks, by means of precast concrete elements, near Hiroshima, Japan (authors' collection)

Numerical simulations by means of the Finite Element Method (FEM) have become a valuable and important tool in the field of Civil Engineering. The application of suitable mathematical algorithms and nonlinear material models allow for the identification of the damage and possible failure modes 
of a structure subjected to any type of loading scenario [15-17]. The necessity of having good FEM models that can match the experimental results is of paramount importance. The benefits of using FEM analysis are manifold: shorter time until the results are obtained, the parameters can be easily changed in order to assess their influence on the behavior of analyzed structural members, etc.

The paper presents the results of numerical simulations on the load carrying capacity of short RC columns strengthened, by means of the jacketing technique, with a novel Cementitious material. The columns were subjected to lateral cyclic loading and the results were compared in terms of peak resisting load and the maximum lateral displacement. The decreased flexibility led to a higher load carrying capacity. The benefit of using the new material resided in smaller added dead weight of the strengthened column compared to classic reinforced concrete or reinforced mortar jacketing.

\section{Materials}

From the structural engineering point of view, it is important to assess the behavior of a building during seismic excitations in order to determine whether or not supplementary measures should be taken before any destructive events occurs in order to prevent the possible collapse of the building. Part of the material data is based on the information obtained from previous research works [18]. Both experimental and numerical simulations are used to calibrate and validate the current FE model developed during the research program.

Concrete. A concrete mix with a design compressive strength of $30 \mathrm{~N} / \mathrm{mm}^{2}$, obtained from uniaxial compression tests at 7 days according to JIS A 1108 [19], was considered. The compressive strength of each concrete batch was measured at the day of testing on five $100 \times 200 \mathrm{~mm}$ cylinders subjected to uniaxial compression.

Reinforcement. The longitudinal reinforcement consisted of 4 ribbed bars, D22 SPBD1170, with the cross sectional area of $387.1 \mathrm{~mm}^{2}$. The yield strength of the bars was experimentally determined to be $f_{y}=1198 \mathrm{~N} / \mathrm{mm}^{2}$. The shear reinforcement was made of D6 SD295 ribbed ties with a nominal cross-sectional area of $31.67 \mathrm{~mm}^{2}$ and yield strength of $350 \mathrm{~N} / \mathrm{mm}^{2}$.

Novel Cementitious Material. As mentioned above, a novel Cementitious material was used for jacketing the RC columns. Standards are continuously developed and are used to determine construction materials compliance with the specification limits. It is now generally accepted that the production of Portland cement, the key ingredient of making concrete, generates a significant amount of carbon dioxide [20]. Still, concrete is the most widely used construction material in the world due to its incredible versatility, availability and relatively low cost.

With the re-emergence of sustainability on the public and political agendas globally, researchers and decision makers might be facing a new round of initiatives, debates and politics on environmental reform $[21,22]$. The novel Cementitious material used in the present research is obtained from industrial wastes, most of them unrecyclable until recently [23]. Its properties, in conjunction with ordinary Portland cement, have been extensively studied in terms of strength and elastic characteristics [13].

Additionally, the effect of curing conditions was also examined [24] and it was concluded that in terms of the self weight a water curing period of 7 days or 14 days led to better values. That means lighter structures and better behavior under seismic excitations. Similar observations were made in terms bending tensile strength and uniaxial compressive strength. The results were encouraging, especially since the presence of moisture during the curing period of time has significant effects on both strength and elastic properties of Cementitious materials [25, 26]. The novel mineral binder proved to be effective in delivering high values for the mechanical properties even in the absence of curing moisture [24]. This is valuable information for cases when the absence of moisture during the curing period of time might be an issue. 


\section{Innovation for Sustainable Development}

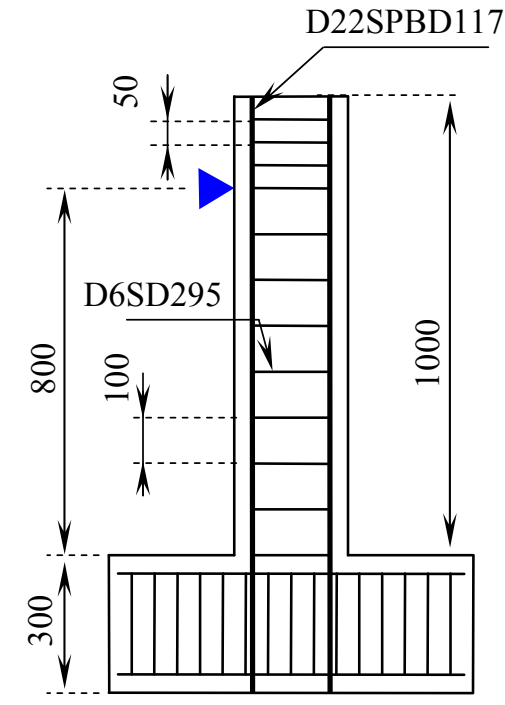

Fig. 4 Specimen geometry and reinforcement layout (unit: $\mathrm{mm}$ )
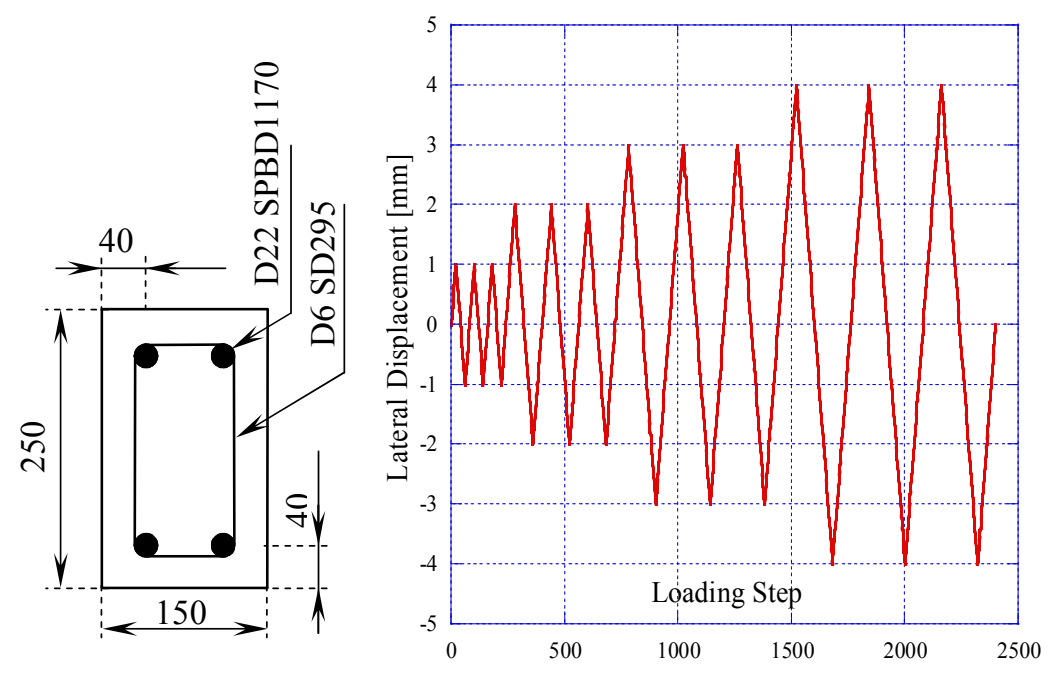

Fig. 5 Cross sectional dimensions (unit: $\mathrm{mm}$ )
Fig. 6 Loading pattern

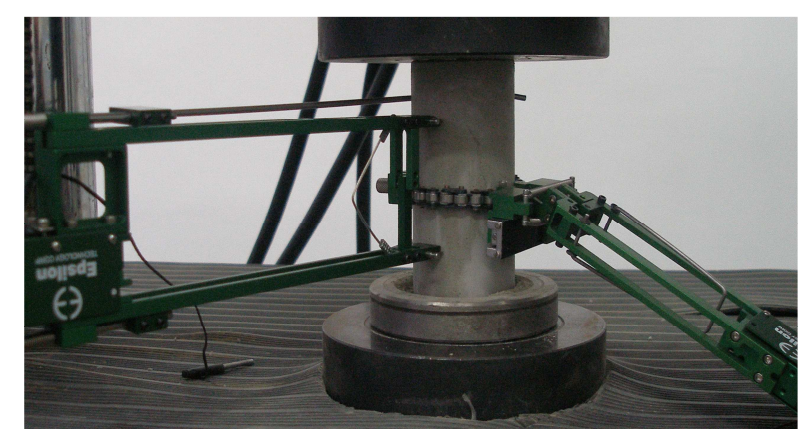

Fig. 7 Experimental determination of the elastic properties of the strengthening material

\section{Experimental Procedure}

Although the original research paper [18] presents the experimental investigation on short $\mathrm{RC}$ columns having various distribution of the shear reinforcement, the present paper uses only one type of specimen for the validation and the calibration of the numerical simulations. The reinforcement layout is presented in Fig. 4 having the cross-section shown in Fig. 5.

The specimen was subjected to lateral cyclic loading until failure which was considered to be reached when the magnitude of the lateral load dropped to $0.6 \times \mathrm{P}_{\max }$. The loading consisted in reaching an increasingly lateral displacement, thus being controlled in terms of displacement. Three loading alternating cycles were performed for each target displacement, as shown in Fig. 6. The loading rate was $0.05 \mathrm{~mm} / \mathrm{sec}$ so that it could be considered a quasi-static load. The range of lateral displacement was $0 \div \pm 30 \mathrm{~mm}$.

The strength characteristics of the jacketing material were experimentally determined for various percentages of Portland cement replacement by the novel Cementitious material [13]. Additionally, the elastic properties were also determined according to ASTM C469 [27] specifications. The loading rate was $0.23 \mathrm{~N} / \mathrm{mm}^{2} / \mathrm{s}$. Before being tested, both ends of the cylinders were ground to ensure a smooth and plane surface. The axial strain was measured with the help of a $50 \mathrm{~mm}$ gage length extensometer, Fig. 7, whereas the transverse strain was measured by means of a circumferential extensometer, also shown in Fig. 7. The values of the elastic properties considered at this stage of the research are presented in Table 1.

Table 1. Strength and elastic properties of the strengthening material (determined at the age of 28 days)

\begin{tabular}{|l|l|l|l|l||}
\hline \multirow{2}{*}{$\begin{array}{l}\text { Mix } \\
\text { Designation }\end{array}$} & $\begin{array}{l}\text { Tensile } \\
\text { strength }\end{array}$ & $\begin{array}{l}\text { Compressive } \\
\text { strength }\end{array}$ & $\begin{array}{l}\text { Modulus of } \\
\text { Elasticity }\end{array}$ & $\begin{array}{l}\text { Poisson's } \\
\text { Coefficient }\end{array}$ \\
\cline { 2 - 5 } & {$[\mathrm{N} / \mathrm{mm} 2]$} & {$[\mathrm{N} / \mathrm{mm} 2]$} & {$[\mathrm{kN} / \mathrm{mm} 2]$} & - \\
\hline \hline C1K30 & 10.01 & 42.15 & 30.98 & 0.201 \\
\hline C1K35 & 9.91 & 43.22 & 31.15 & 0.202 \\
\hline C1K40 & 11.78 & 43.01 & 31.55 & 0.201 \\
\hline
\end{tabular}




\section{Finite Element Analysis}

FE Model. Two-dimensional non-linear numerical simulations were carried out by beams of the FEM software SAP2000 [28]. The column and the footing, Fig. 8a, was modeled using 4-node plane stress elements, presented in Fig. 8b, based on linear interpolation and Gauss integration. The mesh size for the column was $10 \times 10 \mathrm{~mm}$ whereas for the footing it was chosen to be $25 \times 25 \mathrm{~mm}$. The reinforcement was modeled as embedded rebar element having the material properties from [18] and shown by red color in Fig. 8b.

Constitutive Laws. Several models are available in the literature to analyze the confinement effects produced by transverse steel reinforcements on compressed normal and high strength concrete members. The concrete in the column was modeled using two different constitutive laws. The green color in Fig. $7 \mathrm{~b}$ represents the concrete considered using Mander's model for confined concrete [29, 30] whereas the light-blue color, the concrete cover, was modeled using unconfined model. Both models take into account the shear stresses, as shown in Fig. 9a, for confined concrete, and Fig. 9b, for unconfined concrete.

The jacketing material used for strengthening the column was also modeled as a concrete material with the values from Table 1. Given the encouraging results obtained for the strength and elastic properties, the thickness of the strengthening layer was assumed to be $5 \mathrm{~cm}$, only half the usual thickness for jacketing techniques by means of Cementitious materials [31].
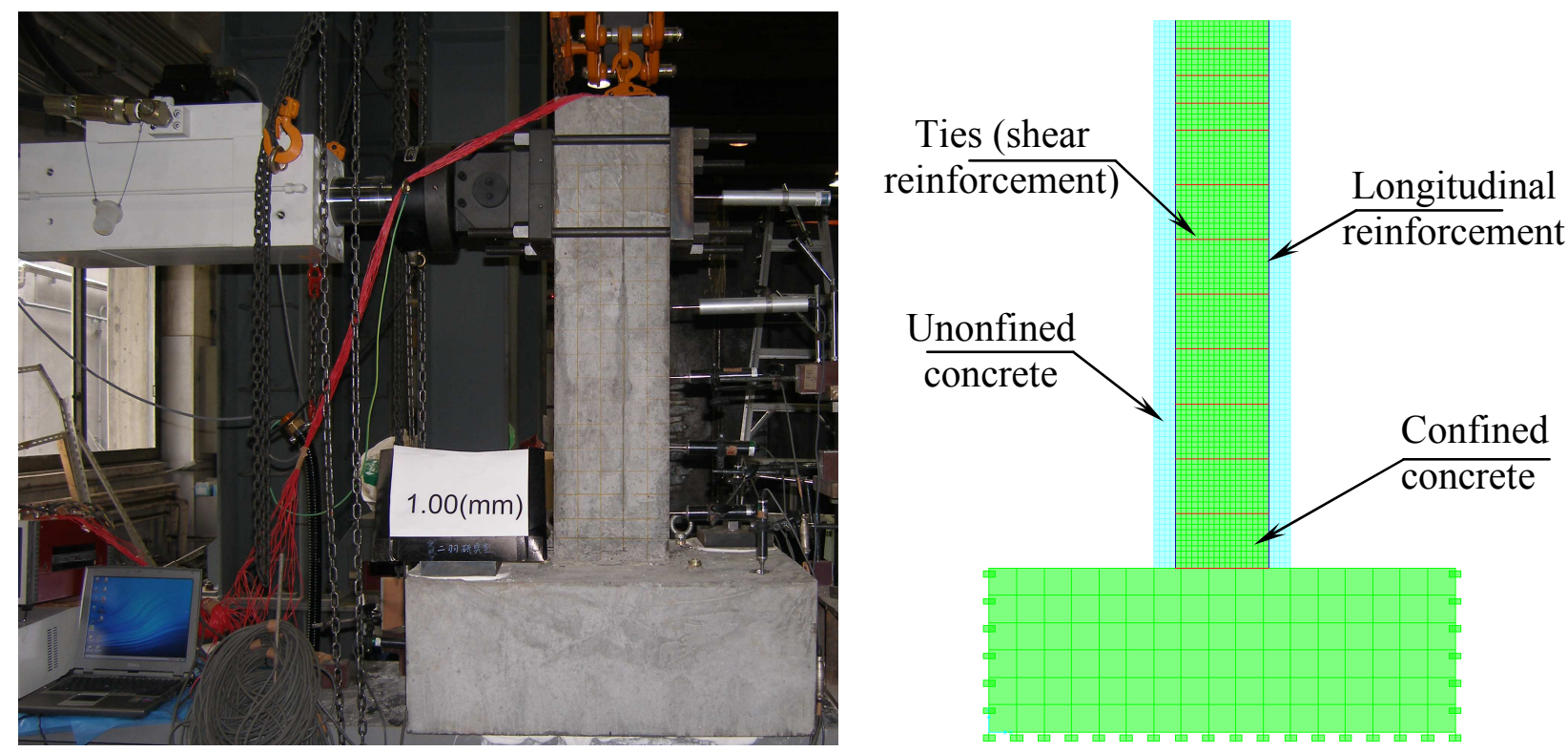

b) Numerical model

Fig. 8 Experimental set-up (a) and the corresponding F.E. Model (b)
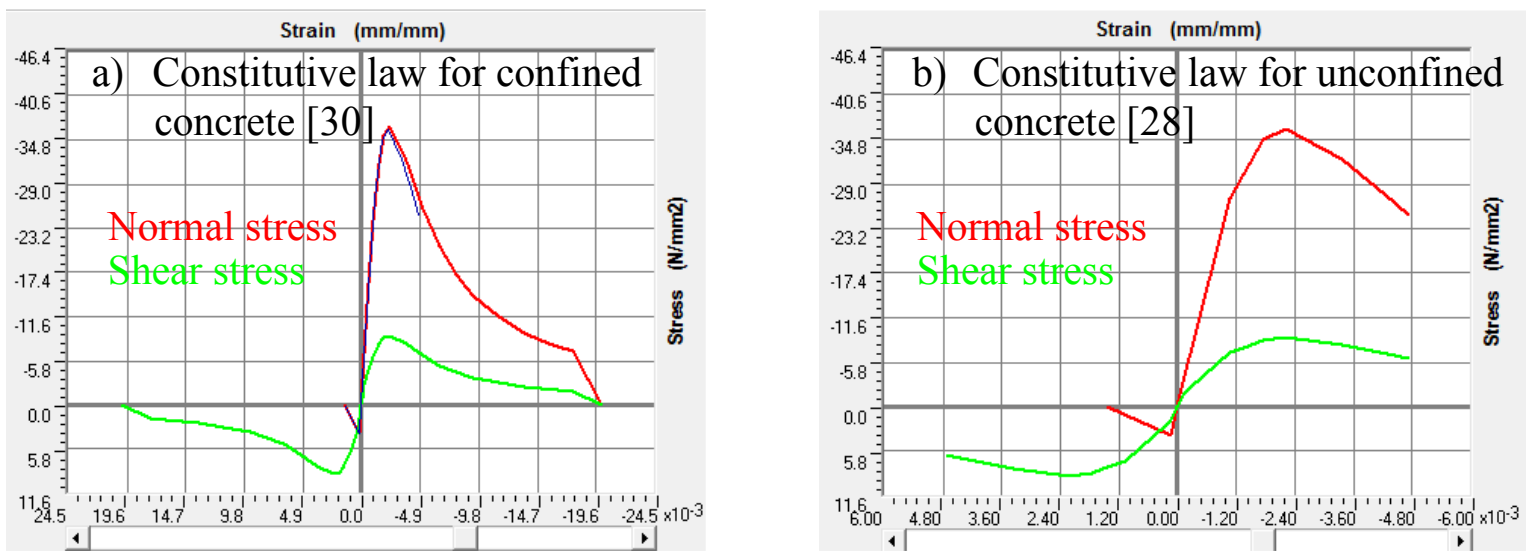

Fig. 9 Constitutive law for concrete: confined (a) and unconfined (b) 


\section{Results and Discussions}

Self Weight. The self weight of the material used for strengthening the columns was determined for various curing conditions. Each specimen was measured using a digital caliper in order to check the compliance with the code specifications. The variation of the prisms dimensions, due to shrinkage or expansion, was within the limits imposed by codes. Right before testing, the specimens were weighted by means of a digital balance with a $0.01 \mathrm{~g}$ precision. The specimens were named according to the cement type used in the mix proportion $\mathrm{C} 1$, for CEM I cement, and depending on the total percentage of industrial waste binder. For example, C1K40 defines the mix proportion made with CEM I cement and 40\% Cementitious material.

Fig. 10 shows that the mix proportions for which the ordinary Portland cement was replaced by ecobinder the self weight is smaller. This observation is valid for every mix proportion and for every curing condition chosen at this stage of the research. The most suitable combination, from the point of view of the self weight, would be the C1K20 and C1K25 mixes cured for either 7 days or 14 days in water. Moreover, it can be observed that the 7 days and 14 days water curing time intervals lead to the lowest values in terms of the self weight for the mix proportions made with Cementitious supplementary material.

Fig. 11 shows the own weight variation in terms of curing conditions and mix proportion. The reference case was considered to be the case of air curing conditions. It can be observed that the $\mathrm{C} 1 \mathrm{~K} 20, \mathrm{C} 1 \mathrm{~K} 25, \mathrm{C} 1 \mathrm{~K} 30$ and $\mathrm{C} 1 \mathrm{~K} 40$ cases showed only minor variations of their own weight for curing periods in water of 7,14 and 21 days. The variation was between $0.05 \%$ and $3 \%$. A similar behavior was recorded for the $\mathrm{C} 1 \mathrm{~K} 35$ case up until the 14 days water curing. A significant gain in self weight was exhibited when all the specimens were kept in water for 28 days.

It can be therefore concluded that, in terms of the self weight, a water curing period of 7 days or 14 days leads to better values. Of course, air curing conditions would lead to even lower values for the self weight but it would be quite detrimental in terms of shrinkage cracking [26].

Even though the obtained results so far are encouraging, the authors deem necessary that further research work should be conducted in this field, especially in the direction of long term influence of novel Cementitious material and ordinary Portland cement on the mechanical properties of mortars. The research should be also extended to the interaction between the mineral matrix and various types of reinforcement. All these should be coupled with an in-depth investigation at the material level to better understand the chemical processes that take place during hardening process of the mineral matrix.

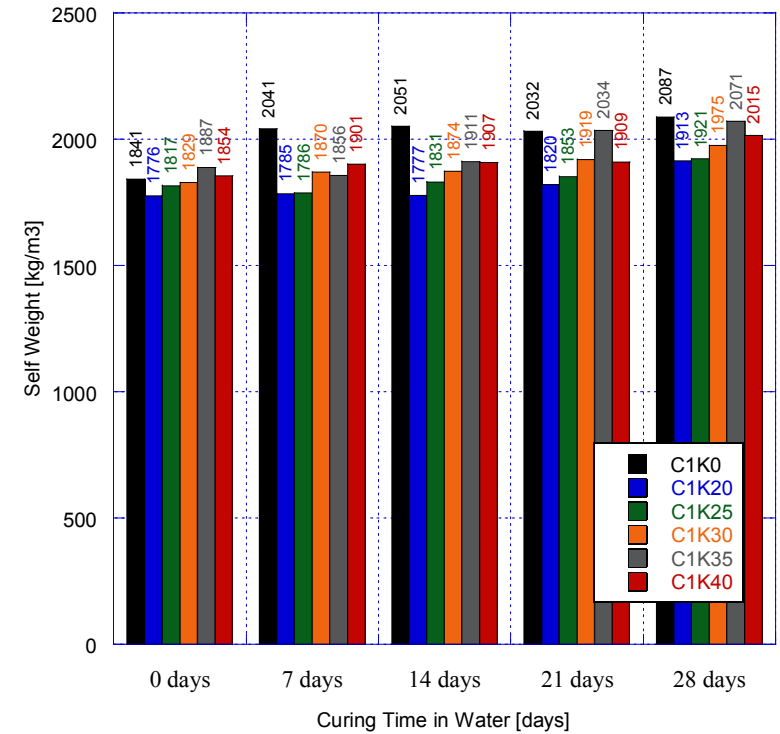

Fig. 10 Self weight as a function of curing conditions [24]

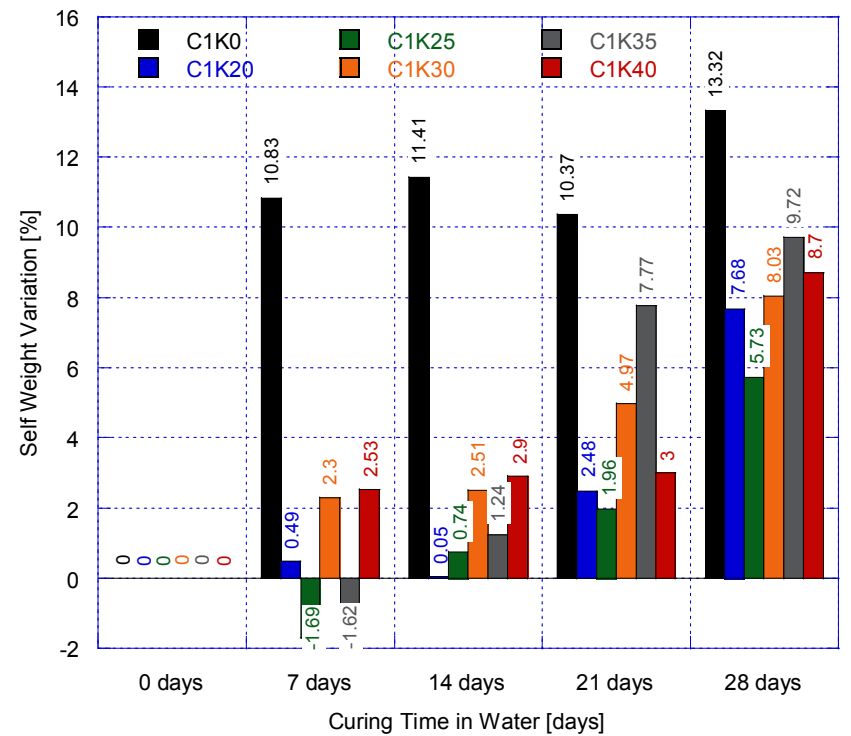

Fig. 11 Variation of self weight for considered mix proportions [24] 
Validation of the Numerical Model. The numerical model of the reference column was subjected to a non-linear static analysis in order to determine the maximum resisted load. The obtained loaddisplacement graph is shown in Fig. 12, for both the analysis and the experiment. It can be observed that, in terms of peak resisting load, the numerical model gives very similar results compared to the experiment. The relative error between the two values is $6 \%(72.11 \mathrm{kN}$ versus $76.72 \mathrm{kN})$ with the FE analysis being on the conservative side.

However, when it comes to the lateral displacement corresponding to the peak load, the numerical results overestimate the experiment by a large amount. This can be explained by the fact that, in the numerical model, a perfect bond between the reinforcement and the concrete was assumed. During the experiment, however, the bond was destroyed and the column resisted only due to the confined concrete core between the longitudinal reinforcements, Fig. 13. A similar behavior should be introduced in the model, as well, in order to be able to simulate the real behavior as accurate as possible.

Peak Resisting Loads and Lateral Displacements. The obtained results by means of non-linear FEA are compared in terms of peak resisting loads and the corresponding displacements. The results are summarized in Table 2.

Peak Load. It can be observed that the increase in the percentage of the novel Cementitious binder [13] leads to an increase in the load carrying capacity of the columns subjected to lateral cyclic loading. However, the increase is not as significant as the increase in the compressive strength of the mortar itself since the majority of the cross-section is made from traditional concrete. Taking into account that the jacketing material is not reinforced, the contribution to the strength gain is quite good.

Lateral Displacement. The corresponding lateral displacement to the peak load is also investigated. The increased stiffness of the jacketing material, represented by a higher value of the modulus of elasticity, Table 1, leads to a decreased value of the lateral displacement corresponding to the peak load. This is an expected phenomenon given the increased overall stiffness of the short column due to jacketing. The increased stiffness is exactly the benefit one would expect in case of a damaged column after an earthquake in order to ensure a proper behavior of the structure during a future seismic event.

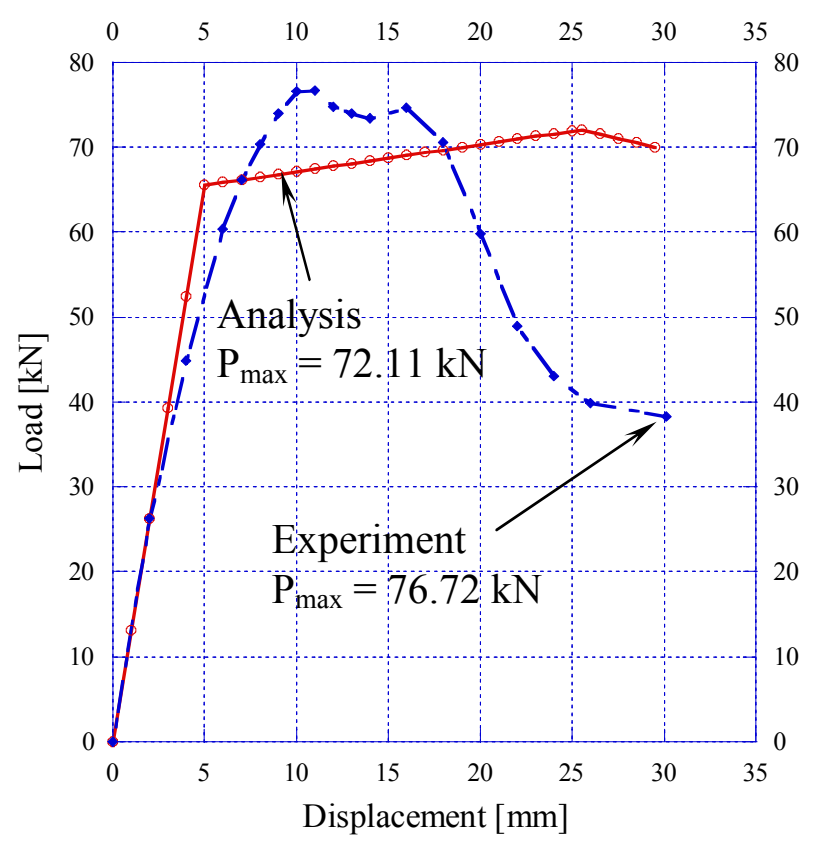

Fig. 12 Numerical analysis vs. experimental results

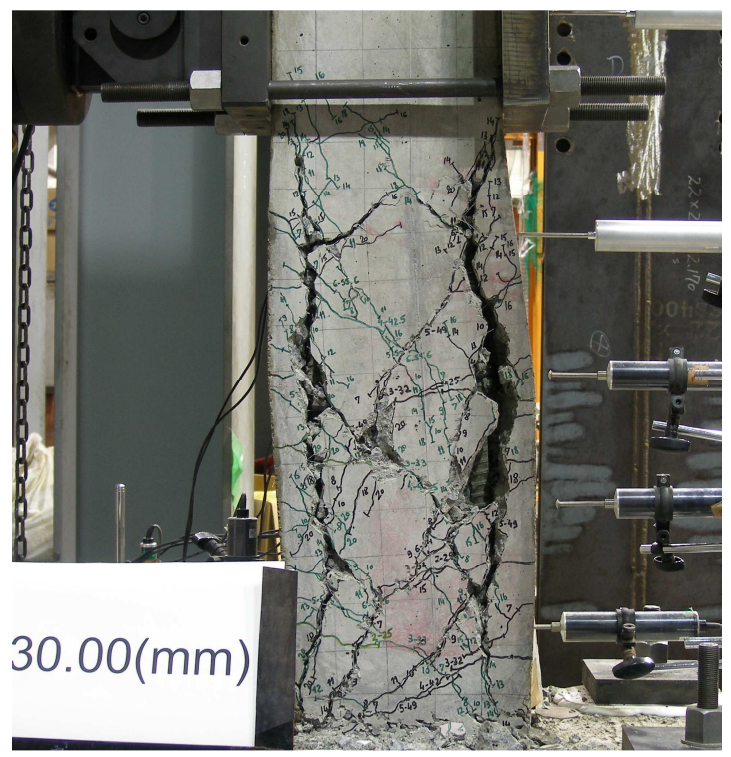

Fig. 13 Specimen at the failure stage 
Table 2. Comparison between experimental values and numerical simulations

\begin{tabular}{||l||l|l|l|l|l||}
\hline \multirow{2}{*}{} & \multirow{2}{*}{ Experiment } & \multicolumn{4}{|c||}{ Finite Element Analysis } \\
\cline { 3 - 6 } & & Reference & Ref.+C1K30 & Ref.+C1K35 & Ref.+C1K40 \\
\hline $\mathrm{P}_{\max }[\mathrm{kN}]$ & 76.72 & 72.11 & 11.24 & 122.17 & 122.98 \\
\hline $\begin{array}{l}\text { Displacement } \\
\text { @ } \mathrm{P}_{\max }[\mathrm{mm}]\end{array}$ & 11.04 & 25.5 & 21.23 & 20.03 & 18.75 \\
\hline
\end{tabular}

The tensile behavior of a similar mineral matrix reinforced with glass fiber composite material was investigated in a previous research work [32] and used in a new building system [33]. The behavior of the strengthened column could be improved by considering the properties of the reinforced mineral matrix which would lead to a higher flexibility and, consequently, the column would be able to dissipate more energy during an earthquake.

\section{Conclusions}

The advancement in science, technology and industrial revolution, had a direct effect on the environmental pollution which has surpassed even the bleakest forecasts both in the developed and the developing countries. With the re-emergence of sustainability on the public and political agendas globally, researchers and decision makers might be facing a new round of initiatives, debates and politics on environmental reform.

The paper presents the results of numerical simulations on the load carrying capacity of short RC columns strengthened, by means of the jacketing technique, with a novel Cementitious material.

Based on the obtained results it can be concluded that analytical results show good agreement with the experimental values in terms of peak resisting loads. However, the corresponding lateral displacements are highly overestimated by the numerical simulations. This can be explained by the fact that, in the numerical model, a perfect bond between the reinforcement and the concrete is assumed. During the experiment, however, the bond was destroyed and the column resisted only due to the confined concrete core between the longitudinal reinforcements. The numerical model should be, thus, further improved to take into account the slip between the reinforcement and the concrete.

The jacketing technique is employed as a method of strengthening short reinforced concrete columns subjected to lateral cyclic loads. Cementitious materials, on the other hand, are widely used in the strengthening and rehabilitation of buildings due to low manufacturing costs and the existence of code provisions. However, the downsides are related to the long duration of the rehabilitation process and the added self weight to the structure. It is now accepted that the production of Portland cement, the key ingredient of making concrete, generates a significant amount of carbon dioxide. Still, concrete is the most widely used construction material in the world due to its incredible versatility, availability and relatively low cost.

A novel Cementitious material is used as partial replacement, in high percentages, of the ordinary Portland cement. As shown by previous research works and literature survey, the resulted mineral matrix exhibits high early strength, very small geometrical variations as well as improved elastic characteristics. The analytical results show that a thinner jacked made of the new mineral matrix can lead to an increase of up to $60 \%$ in the load carrying capacity of analyzed short RC columns. In view of the general concern related to the environmental footprint of the construction industry, as well as the concept of sustainable development, the obtained results strongly recommend the use of the eco-cement as partial replacement of ordinary Portland cement.

\section{Acknowledgement}

This paper was supported by the project "Development and support of multidisciplinary postdoctoral programmes in major technical areas of national strategy of Research - Development Innovation" 4D-POSTDOC, contract no. POSDRU/89/1.5/S/52603, project co-funded by the European Social Fund through Sectorial Operational Programme Human Resources Development 2007-2013. 


\section{References}

[1] M. Moretti, T.P. Tassios, Behaviour of short columns subjected to cyclic shear displacements: Experimental results, Eng Struct, 29 (2007) 2018-2029.

[2] E. Vintzileou, T.P. Tassios, M. Chronopoulos, Experimental validation of seismic code provisions for RC columns, Eng Struct, 29 (2007) 1153-1164.

[3] Information on http://nisee.berkeley.edu/taiwan/mahin/index.html

[4] Information on http://www.nexus.globalquakemodel.org/gem-buildingtaxonomy/overview/glossary/short-column

[5] G. Campione, M. Fossetti, M. Papia, Behavior of Fiber-Reinforced Concrete Columns under Axially and Eccentrically Compressive Loads, Aci Struct J, 107 (2010) 272-281.

[6] G. Campione, G. Minafo, Compressive behavior of short high-strength concrete columns, Eng Struct, 32 (2010) 2755-2766.

[7] E. Vintzileou, A. Stathatos, Assessment of the seismic behaviour of RC columns, Eng Struct, 29 (2007) 1296-1311.

[8] M.H. Harajli, Bond strengthening of lap spliced reinforcement using external FRP jackets: An effective technique for seismic retrofit of rectangular or circular RC columns, Constr Build Mater, 23 (2009) 1265-1278.

[9] O. Ozcan, B. Binici, G. Ozcebe, Seismic strengthening of rectangular reinforced concrete columns using fiber reinforced polymers, Eng Struct, 32 (2010) 964-973.

[10] M. Mouli, H. Khelafi, Strength of short composite rectangular hollow section columns filled with lightweight aggregate concrete, Eng Struct, 29 (2007) 1791-1797.

[11] A. Momayez, M.R. Ehsani, A.A. Ramezanianpour, H. Rajaie, Comparison of methods for evaluating bond strength between concrete substrate and repair materials, Cement Concrete Res, 35 (2005) 748-757.

[12] F. Qiao, C.K. Chau, Z.J. Li, Property evaluation of magnesium phosphate cement mortar as patch repair material, Constr Build Mater, 24 (2010) 695-700.

[13] I.O. Toma, G. Taranu, A.M. Toma, M. Budescu, Influence of cement and sand type on the strength characteristics of mortars with various contents of green binder, Procedia Engineer, 21 (2011) 196-203.

[14] I.O. Toma, D. Covatariu, G. Taranu, M. Budescu, Early-age mechanical properties of mortars with different percentages of eco-cement, Bulletin of The Polytechnic Institute of Jassy Construction Architecture Section, LVII (LXI) (2011) 155-166.

[15] D. Palermo, F.J. Vecchio, Simulation of cyclically loaded concrete structures based on the finite-element method, J Struct Eng-Asce, 133 (2007) 728-738.

[16] U. Kim, R.T. Leon, T.V. Galambos, 3-D nonlinear dynamic behavior of steel joist girder structures, Eng Struct, 31 (2009) 268-274.

[17] S. Grange, P. Kotronis, J. Mazars, Numerical modelling of the seismic behaviour of a 7-story building: NEES benchmark, Mater Struct, 42 (2009) 1433-1442.

[18] I.O. Toma, T. Kimura, K. Watanabe, J. Niwa, Shear Failure of Short Cantilever RC Columns under Cyclic Loading: Experiments and Analysis, in: Proceedings of 5th International Conference on Urban Earthquale Engineering, Tokyo, Japan, 2008, pp. 227-233.

[19] JIS A 1108:2006 - Method of test for compressive strength of concrete, in, Japanese Industrial Standard, 2006.

[20] J.S. Damtoft, J. Lukasik, D. Herfort, D. Sorrentino, E.M. Gartner, Sustainable development and climate change initiatives, Cement Concrete Res, 38 (2008) 115-127.

[21] G. Spaargaren, A.P.J. Mol, Greening global consumption: Redefining politics and authority, Global Environ Chang, 18 (2008) 350-359.

[22] J.K. Hall, G.A. Daneke, M.J. Lenox, Sustainable development and entrepreneurship: Past contributions and future directions, J Bus Venturing, 25 (2010) 439-448.

[23] M. Garg, A.K. Minocha, N. Jain, Environment hazard mitigation of waste gypsum and chalk: Use in construction materials, Constr Build Mater, 25 (2011) 944-949. 
[24] I.O. Toma, D. Covatariu, A.M. Toma, G. Taranu, M. Budescu, Greening of Concrete Industry by Incorporating Gypsum-Based Industrial Wastes as Supplementary Cementitious Materials, Advanced Materials Research, 649 (2013) 246-249.

[25] F. Sajedi, H.A. Razak, Effects of curing regimes and cement fineness on the compressive strength of ordinary Portland cement mortars, Constr Build Mater, 25 (2011) 2036-2045.

[26] A. Itim, K. Ezziane, E.H. Kadri, Compressive strength and shrinkage of mortar containing various amounts of mineral additions, Constr Build Mater, 25 (2011) 3603-3609.

[27] ASTM C469 / C469M - Standard Test Method for Static Modulus of Elasticity and Poisson's Ratio of Concrete in Compression, American Society for Testing and Materials, 2010.

[28] C.S.I., SAP2000 - Integrated Software for Structural Analysis \& Design, Computers and Structures Inc, Berkeley, California, USA, http://www.csiberkeley.com/sap2000/overview, 2011.

[29] M.M. Karthik, J.B. Mander, Stress-Block Parameters for Unconfined and Confined Concrete Based on a Unified Stress-Strain Model, J Struct Eng-Asce, 137 (2011) 270-273.

[30] J.B. Mander, M.J.N. Priestley, R. Park, Theoretical stress-strain model for confined concrete, J Struct Eng ASCE, 114 (1988) 1804-1826.

[31] A.D. Espeche, J. Leon, Estimation of bond strength envelopes for old-to-new concrete interfaces based on a cylinder splitting test, Constr Build Mater, 25 (2011) 1222-1235.

[32] G. Taranu, I.O. Toma, R. Plesu, I. Gradinariu, M. Budescu, Experimental Evaluation of Elastic Modulus of Unreinforced and Glass Fibre Reinforced Mineral Matrix Composite, Proceedings of ICEUBI2011 - International Conference on Engineering, Covilha, Portugal, 2011.

[33] G. Taranu, M. Budescu, R. Plesu, I.O. Toma, A New Building System Made of Glass Fiber Reinforced Mineral Matrix Composites, Advanced Materials Research, 649 (2013) 25-28. 